\title{
GENETIC EFFECTS OF MATERNAL INBREEDING IN MAN ON CONGENITAL ABNORMALITY, MENTAL DEFECT, INFERTILITY, AND PRENATAL DEATH*
}

\author{
(The Japan Society of Human Genetics Award Lecture) \\ Katumi TANAKA \\ Department of Human Genetics, Medical Research Institute, \\ Tokyo Medical and Dental University, Tokyo
}

\section{INTRODUCTION}

There are the well known effects of maternal age, parity, seasons, nutrition, and many other factors which influence the condition of fetuses. Genotypes of the mothers, also, are important components of the maternal effects on the fetuses, as pointed out, for instance, by Fraser $(1961,1974)$. Some genotypes of the mothers may cause anatomical, physiological or biochemical changes in their bodies, which in turn produce adverse effects on the fetal environment or increase susceptibility of fetuses to harmful agents inducing fetal, perinatal or neonatal deaths, or congenital abnormalities in genotypically normal fetuses. Births of malformed and mentally deficient children from phenylketonuric mothers is one of the most remarkable examples (Fisch and Anderson, 1971; Pitt and Gooch, 1974). In these occassions mothers having such genotypes may manifest some abnormal signs or may appear almost normal.

Studies on experimental and domestic animals suggest that a considerable proportion of such genotypes in man, if any, may be autosomal recessive homozygotes. Thus, it is very probable that a consanguineous union of a woman's parents may influence her children (or grandchildren of the related couple) through her increased homozygosity, as in the case of phenylketonuric mothers, about $35 \%$ of whom are products of first cousin marriage in Japan (Tanaka, 1968).

However, genetic studies on the effects of consanguineous marriages in man have almost entirely been focussed on the attributes of children born to such marriages. It is also to be noticed that few attempts have been made to clarify the

* The Japan Society of Human Genetics Award Lecture, presented at the 21th Annual Meeting of the Society in Kyoto on November 19th, 1976.

This study was supported by Scientific Research Grants from the Ministry of Education, Science and Culture in 1962-1968, a Grant from the Toyo Rayon Foundation for the Promotion of Science and Technology in 1965-1967, and a Grant from the Ministry of Health and Welfare for the Research on Handicapped Children in 1974-1976. 
effects of consanguineous marriage on the fertility of offspring born to such marriages.

The present author and his colleagues reported previously possible effects of increased homozygosity due to consanguineous marriages on the infertility in offspring of such marriages, and mortality and morbidity in grandchildren of such marriages (Tanaka, 1964, 1966a, b, 1967, 1968, 1972; Tanaka et al., 1964, 1965, 1967, 1968). The present communication deals with the reinvestigation of the data and interpretation of results of the analyses.

In this paper the term "inbred one" will refer to the product of a consanguineous marriage and the term "inbreeding effects" refer to the effects on characteristics of offspring one or the other of whose parent is inbred, i.e. the product of a consanguineous marriage.

\section{EFFECTS OF MATERNAL INBREEDING ON CONGENITAL ABNORMALITIES AND MENTAL RETARDATION}

This study was carried out under the presumption that effects of some unfavorable intra-uterine environments due to increased homozygosity in maternal genotype on the morbidity in the fetuses, if any, could be detected if the consanguinity rate among the maternal grandparents of the patients with congenital abnormalities (cerebral palsy and hip joint dislocation) or mental retardation is significantly higher than the rate among the paternal grandparents. Similar data on paralytic poliomyelitics, albinos, and phenylketonurics were also analyzed.

\section{Materials and Methods}

Lists of patients affected with cerebral palsy, congenital dislocation of the hip, or paralytic poliomyelitis were obtained at three public institutions for crippled children in Shizuoka Prefecture. Also a list of severe mental defectives was supplied by the Section of Child Welfare, Shizuoka Prefectural Government. Of 1,084 crippled subjects in the lists, those who had two or more of the three disorders (cerebral palsy, congenital hip dislocation and paralytic poliomyelitis) were excluded from the analyses. Of the 784 mental defectives in the list, Down's syndrome, cerebral palsy, epilepsy, other known hereditary syndromes, psychopathics accompanying with mental defect, and those whose defect was reported to have been acquired postnatally after head injuries, infections such as encephalitis, etc. were excluded. Family registers of a number of patients were not found at the reported registration offices. Thus, in all 986 sibships with 992 crippled children and 292 sibships with 303 mental defectives were subjected to this study.

Informations on the cases of albinism were obtained by sending questionnaires to 69 schools and institutions for the blind in Japan and through a survey of all primary and middle school children $(172,273$ in total) in the East district of Shizuoka Prefecture. Phenylketonuric cases were collected by a survey in all the institutions for mental defectives in Japan, by referring to pertinent medical literature and by the 
courtesy of Dr. T. Oura, Osaka Pediatric Center. Details of the data on albinism and phenylketonuria were reported elsewhere (Tanaka and Watanabe, 1967; Tanaka et al., 1961 and Tanaka, 1968).

Consanguinity between patients' parents, between paternal grandparents, and between maternal grandparents was ascertained through study of family registers, koseki.

Difficulty in the estimation of consanguinity rate by means of koseki study

To ascertain consanguinity between parents of an individual by means of koseki, at least one common ancestor must be found in the paternal and maternal lines. For instance, if the same couple is found among paternal and maternal great-grandparents, the parents of the propositus are ascertained to be full first cousins. However, it is not always possible to obtain necessary informations on the ancestors by koseki study.

As shown in Fig. 1, if the record on one great-grandparent couple cannot be found, the probability of ascertaining a first-cousin marriage is reduced by $1 / 2$, and if two couples, one in the paternal and the other in the maternal line, are missing, the probability is reduced by $1 / 4$. If two couples, both in the same line, or more couples are missing, no first-cousin marriage can be ascertained. Thus, if families with missing ancestors are included in the sample, a simple calculation of the rate of firstcousin marriage gives an underestimate of the true rate, unless an appropriate correction is applied. The necessity of such a correction is greater for the estimation of consanguinity rate in the grandparents in which one more ancestral generation

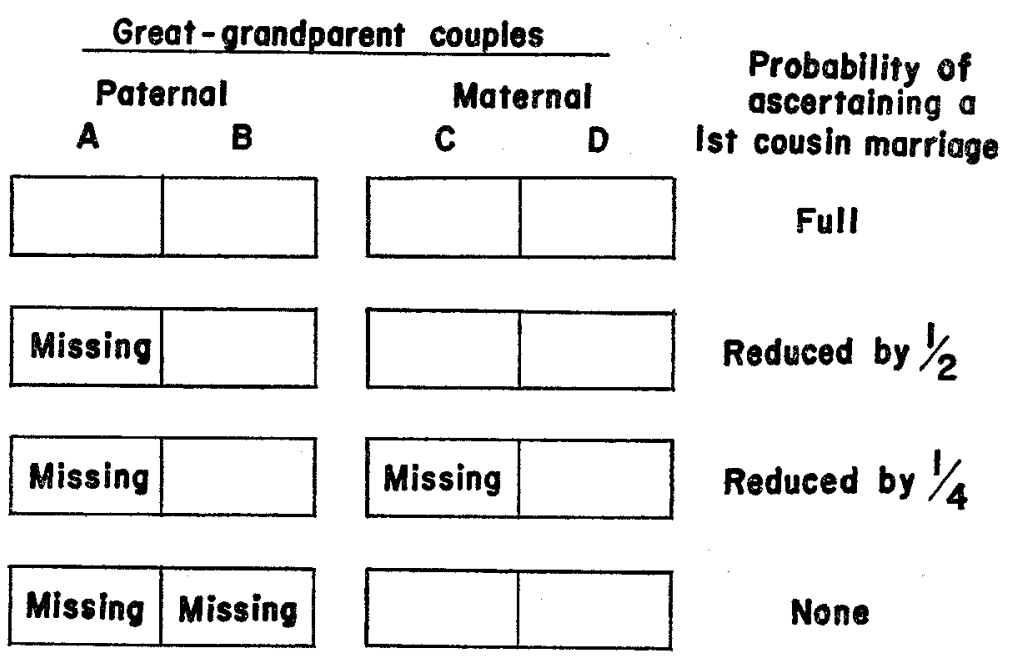

Fig. 1. Reduction of probability of ascertaining a first-cousin marriage due to missing of family registers of great-grandparents. 
must be studied and, accordingly, a higher missing rate is expected than for that in the parents.

Moreover, the missing in koseki records introduces a systematic error into the estimate of the consanguinity rate as pointed out by the present author (Tanaka, 1971). He proposed two extreme models: if the parents have a common ancestor, the common ancestor may be missing in tracing back from the father of the propositus irrespective as to whether the common ancestor is missing or not in tracing back from the mother (Model I), or the common ancestor may be always concurrently missing in both paternal and maternal lines (Model II). Obviously different correction methods should be applied according to which model is appropriate. Detailed methods for the correction of the errors and discussions are shown in his paper (1971).

\section{Results}

In the present study, several comparisons were made between the estimated rates of first-cousin marriage in paternal and maternal grandparents calculated under various assumptions. All the results indicate substantially the same trend. For

Table 1. Rate of first-cousin marriage among parents, paternal grandparents, and maternal grandparents of patients affected with abnormalities.

\begin{tabular}{|c|c|c|c|c|c|}
\hline \multirow[t]{2}{*}{ Conditions } & & $\begin{array}{c}\text { (a) } \\
\text { Parents }\end{array}$ & $\begin{array}{c}\text { (b) } \\
\text { Paternal } \\
\text { grandparents }\end{array}$ & $\begin{array}{c}\text { (c) } \\
\text { Maternal } \\
\text { grandparents }\end{array}$ & $\begin{array}{l}\text { Probability } \\
\text { of difference } \\
\text { between } \\
\text { (b) and (c) }\end{array}$ \\
\hline & $N$ & 436.5 & 359.75 & 372.75 & \\
\hline \multirow[t]{2}{*}{ Cerebral palsy } & M & 40 & 12 & 25 & $0.02-0.05$ \\
\hline & $\%$ & 9.16 & 3.34 & 6.71 & \\
\hline \multirow{4}{*}{$\begin{array}{l}\text { Congenital dislocation } \\
\text { of the hip joint }\end{array}$} & $\mathbf{N}$ & 185.5 & 150.25 & 152.5 & \\
\hline & M & 14 & 5 & 10 & $0.2-0.3$ \\
\hline & $\%$ & 7.55 & 3.33 & 6.56 & \\
\hline & $\mathrm{N}$ & 313.25 & 220.0 & 232.75 & \\
\hline \multirow[t]{3}{*}{ Paralytic poliomyelitis } & M & 14 & 10 & 4 & $0.1-0.2$ \\
\hline & $\%$ & 4.47 & 4.55 & 1.72 & \\
\hline & $\mathrm{N}$ & 245.75 & 194.5 & 204.75 & \\
\hline \multirow[t]{3}{*}{ Severe mental defect } & $\mathbf{M}$ & 19 & 14 & 8 & $0.1-0.2$ \\
\hline & $\%$ & 7.73 & 7.20 & 3.91 & \\
\hline & $\mathbf{N}$ & 121.5 & 78.25 & 85.5 & \\
\hline \multirow[t]{3}{*}{ Albinism } & M & 62 & 6 & 7 & $0.9-0.95$ \\
\hline & $\%$ & 51.03 & 7.67 & 8.19 & \\
\hline & $\mathrm{N}$ & 58.5 & 43.0 & 43.0 & \\
\hline \multirow[t]{2}{*}{ Phenylketonuria } & M & 20 & 1 & 2 & \\
\hline & $\%$ & 34.19 & 2.33 & 4.65 & \\
\hline
\end{tabular}

$\mathrm{N}$ : Number of couples corrected considering the reduction of information due to missing of koseki records $\left(=n_{0}+n_{1} / 2+n_{2} / 4\right.$, see text).

M: Number of ascertained first-cousin matings. 
example, the results obtained by assuming Model I and excluding families with missing ancestors are shown in Table 1.

In this method the rates of first-cousin marriage between parents of the propositi are calculated by following formula:

$$
c=\frac{M}{n_{0}+n_{1} / 2+n_{2} / 4},
$$

where $M$ denotes the number of ascertained first-cousin marriages, and $n_{0}, n_{1}$ and $n_{2}$, respectively, numbers of parents whose four, three and two (one in the paternal and the other in the maternal line) great-grandparent couples are identified by the koseki study. The rates of first-cousin marriage between paternal grandparents and those between maternal grandparents are similarly estimated.

The table shows that the frequency of first-cousin marriages among the maternal grandparents of the cerebral palsy patients is significantly higher than that among the paternal grandparents. A similar trend is shown in the congenital dislocation of the hip joint, but the difference is insignificant. On the other hand, no indication of maternal inbreeding effects is observed for paralytic poliomyelitis, severe mental deficiency, albinism and phenylketonuria.

\section{EFFECT OF MATERNAL INBREEDING ON PRENATAL DEATHS}

\section{Data}

Information on reproductive history was collected by Dr. T. Furusho and others through interviews and questionnaires for all couples residing in two rural communities in Kyushu Island: one, named $K$ population, in Fukuoka Prefecture and the other, named $U$ population, in Kumamoto Prefecture.

Each history includes details about all recognized pregnancies of the woman interviewed, who was specifically asked about miscarriages and induced abortions. Consanguinity between spouses, parents of husbands and parents of wives were also recorded through interviews. Data on consanguinity and liveborn children were checked by referring to koseki records.

For the purpose of getting more homogeneous samples for socioeconomic status, the following few families were excluded from the analyses: 1) families engaging in occupations other than farming; 2) those whose legal residence, honseki-chi, were outside the communities in question or their adjacent villages, since the majority of these families are immigrants; 3) families whose wife had experienced one or more induced abortion, since the rate of the natural abortion and stillbirth in such families is significantly higher than the average.

If the remaining sample is classified according to year of marriage, significantly lower prenatal mortality rates are obtained for couples married before 1930 than those for later married couples. The rate of prenatal deaths in the whole nation was $9 \%$ or higher in 1900-1904, the rate had gradually decreased to some $5 \%$; and there has been no substantial change in the rate for the recent forty years if induced 
Table 2. Rate of prenatal death in the groups classified according to whether the spouses, husband's parents and wife's parents are related or not.

\begin{tabular}{|c|c|c|c|c|c|c|c|c|}
\hline \multirow{3}{*}{$\begin{array}{c}\text { spouses } \\
\text { Fo }_{0}\end{array}$} & \multicolumn{2}{|c|}{$\begin{array}{c}\text { Consanguinity } \\
\text { between }\end{array}$} & \multicolumn{3}{|c|}{$\mathbf{K}$ population } & \multicolumn{3}{|c|}{$\mathrm{U}$ population } \\
\hline & \multirow{2}{*}{$\begin{array}{c}\text { husband's } \\
\text { parents } \\
\text { Fp }_{p}\end{array}$} & \multirow{2}{*}{$\begin{array}{c}\text { wife's } \\
\text { parents } \\
F_{m}\end{array}$} & \multirow{2}{*}{$\begin{array}{l}\text { No. of } \\
\text { preg- } \\
\text { nancies }\end{array}$} & \multicolumn{2}{|c|}{$\begin{array}{c}\text { Prenatal } \\
\text { death }\end{array}$} & \multirow{2}{*}{$\begin{array}{c}\text { No. of } \\
\text { preg- } \\
\text { nancies }\end{array}$} & \multicolumn{2}{|c|}{$\begin{array}{c}\text { Prenatal } \\
\text { death }\end{array}$} \\
\hline & & & & No. & $\%$ & & No. & $\%$ \\
\hline 0 & 0 & 0 & 1,547 & 56 & 3.62 & 648 & 46 & 7.10 \\
\hline 0 & + & 0 & 87 & 3 & 3.45 & 148 & 9 & 6.08 \\
\hline 0 & 0 & + & 125 & 3 & 2.40 & 67 & 7 & 10.45 \\
\hline 0 & + & + & 44 & 2 & 4.55 & 7 & 1 & 14.29 \\
\hline+ & 0 & 0 & 382 & 11 & 2.88 & 117 & 9 & 7.69 \\
\hline+ & + & 0 & 47 & 1 & 2.13 & 20 & 0 & 0 \\
\hline$\div$ & 0 & + & 37 & 2 & 5.41 & 13 & 0 & 0 \\
\hline+ & + & + & 64 & 5 & 7.81 & 4 & 0 & 0 \\
\hline Total & & & 2,333 & 83 & 3.56 & 1,024 & 72 & 7.03 \\
\hline
\end{tabular}

abortions are excluded. Therefore, the reported low mortality rate in the early married group is very likely a reflection of a lessened recall. Accordingly, it seems safe to use only the data from the couples who had married in 1931 or later. Thus, 2,333 pregnancies in $\mathrm{K}$ population and 1,024 pregnancies in $\mathrm{U}$ population were available for analyses.

\section{Analyses and Results}

The samples were classified into 8 groups according to whether the fetuses, the husbands, or the wives are inbred or not; in other words, according to whether the spouses, husbands' parents or wives' parents were related or not, irrespective of the degree of consanguinity. As shown in Table 2 it is suggestive that the rate of prenatal mortality is increased with maternal inbreeding but not with fetal inbreeding. However, none of the differences is statistically significant.

A more precise evaluation of the inbreeding effects can be made by regression analyses. The data are approximated to a linear regression model:

where $\mathrm{Y}$ denotes the prenatal mortality rate,

$$
Y=A+B_{0} F_{o}+B_{p} F_{p}+B_{m} F_{m}
$$

A its mean,

$F_{o}, F_{p}$, and $F_{m}$ are respectively coefficients of inbreeding of the fetus, the husband, and the wife, and

$B_{o}, B_{p}, B_{m}$ are respectively regression coefficients for the inbreeding coefficient on prenatal mortality rate.

At first, all data were used for the analyses. Next the data excluding $(0,0,0)$ group, in which $F_{o}, F_{p}$, and $F_{m}$ are all 0 , were similarly analyzed, taking into consideration that the group may possibly be somewhat different from other consanguinity groups in socioeconomic status. 
Table 3. Effects of inbreeding on fetal mortality. Results of regression analyses approximating to $\mathrm{Y}=\mathrm{A}+\mathrm{B}_{\mathrm{o}} \mathrm{F}_{\mathrm{o}}+\mathrm{B}_{\mathrm{p}} \mathrm{F}_{\mathrm{p}}+\mathrm{B}_{\mathrm{m}} \mathrm{F}_{\mathrm{m}}$

\begin{tabular}{|c|c|c|c|c|c|}
\hline & & \multicolumn{2}{|c|}{$\mathbf{K}$ population } & \multicolumn{2}{|c|}{ U population } \\
\hline & & Whole sample & $(0,0,0)$ excluded & Whole sample & $(0,0,0)$ excluded \\
\hline A & & 0.0345 & 0.0205 & 0.0749 & 0.0926 \\
\hline $\mathrm{B}_{\mathrm{o}}$ & & -0.0256 & 0.1434 & -0.5158 & -0.6784 \\
\hline $\mathbf{B}_{p}$ & & 0.1792 & 0.2458 & -0.3366 & -0.5312 \\
\hline $\mathbf{B}_{m}$ & & 0.0512 & 0.1792 & 0.3917 & 0.1728 \\
\hline \multirow{3}{*}{ B/A ratios } & $\left(\mathrm{B}_{0} / \mathrm{A}\right.$ & - & 7.0 & - & - \\
\hline & $\mathrm{B}_{\mathrm{p}} / \mathrm{A}$ & 5.2 & 12.0 & 一 & - \\
\hline & $\mathrm{Bm} / \mathrm{A}$ & 1.5 & 8.7 & 5.2 & 1.9 \\
\hline
\end{tabular}

Table 4. Effects of inbreeding on fetal mortality. Results of regression analyses disregarding the effect of husband's inbreeding $\mathrm{Y}=\mathrm{A}+\mathrm{B}_{\mathrm{o}} \mathrm{F}_{\mathrm{o}}+\mathrm{B}_{\mathrm{m}} \mathrm{F}_{\mathrm{m}}$

\begin{tabular}{|c|c|c|c|c|c|}
\hline & & \multicolumn{2}{|c|}{$\mathrm{K}$ population } & \multicolumn{2}{|c|}{ U population } \\
\hline & & Whole sample & $(0,0)$ excluded & Whole sample & $(0,0)$ excluded \\
\hline A & & 0.0348 & 0.0258 & 0.0715 & 0.0734 \\
\hline Bo & & -0.0102 & 0.0973 & -0.4531 & -0.4902 \\
\hline $\mathrm{B}_{\mathrm{m}}$ & & 0.1357 & 0.2278 & 0.3942 & 0.3661 \\
\hline \multirow{2}{*}{$\mathrm{B} / \mathrm{A}$ ratios } & /Bo/A & 一 & 3.8 & - & - \\
\hline & $\mathrm{B}_{\mathrm{m}} / \mathrm{A}$ & 3.9 & 8.8 & 5.5 & 5.0 \\
\hline
\end{tabular}

The results of the regression analyses are summarized in Table 3 . In all the four analyses the prenatal mortality is consistently increased with the increased degree of inbreeding in wives, though none of the regression coefficients is significantly larger than 0 , obviously owing to smallness of the samples and rather large variances. On the other hand the prenatal death is decreased with the increased fetal inbreeding in all but one calculation, and the relationship between the prenatal mortality rate and inbreeding of husbands shows an opposite tendency in the two populations. The situation of $F_{o}$ and $F_{m}$ does not change, if similar regression analyses are carried out disregarding the effect of the husband's inbreeding (Table 4).

\section{EFFECTS OF INBREEDING ON FERTILITY}

\section{Data}

Information on reproductive performances for all married couples residing in two adjacent rural communities in the southern district of Fukuoka Prefecture, Kyushu was collected by Dr. T. Yanase and his colleagues, and Dr. T. Furusho through interviews, koseki records and other public health records. The data include consanguinity between spouses, between parents of husbands and between parents of wives, and marital and reproductive histories, occupations, etc. The information on consanguinity, marital status and livebirths was checked by koseki study. The 
Table 5. Rate of infertility in the groups classified according to whether the spouses, husband's parents and wife's parents are related or not.

\begin{tabular}{|c|c|c|c|c|c|}
\hline \multicolumn{3}{|c|}{ Consanguinity between } & \multirow{2}{*}{$\begin{array}{l}\text { No. of } \\
\text { marriage }\end{array}$} & \multicolumn{2}{|c|}{ Infertile marriage } \\
\hline $\begin{array}{l}\text { spouses } \\
\left(F_{0}\right)\end{array}$ & $\begin{array}{l}\text { parents of husband } \\
\left(F_{p}\right)\end{array}$ & $\begin{array}{c}\text { parents of wife } \\
\left(F_{m}\right)\end{array}$ & & No. & $\frac{\text { rrage }}{\%}$ \\
\hline 0 & 0 & 0 & 1,104 & 52 & 4.71 \\
\hline 0 & + & 0 & 107 & 2 & 1.87 \\
\hline 0 & 0 & + & 82 & 3 & 3.65 \\
\hline 0 & + & + & 23 & 1 & 4.35 \\
\hline Total & & & 1,316 & 58 & 4.41 \\
\hline+ & 0 & 0 & 238 & 7 & 2.94 \\
\hline+ & + & 0 & 37 & 0 & 0 \\
\hline+ & 0 & + & 39 & 2 & 5.13 \\
\hline+ & + & + & 32 & 3 & 9.38 \\
\hline Total & & & 346 & 12 & 3.47 \\
\hline Grand to & & & 1,662 & 70 & 4.21 \\
\hline
\end{tabular}

following analyses were carried out using pooled data on the two communities which were quite similar in socioeconomic status.

\section{Analyses and Results}

A total of 1,662 couples cohabiting for five years or longer were subjected to the analyses. Of the couples, 70 wives have never been pregnant. The rates of these infertile marriages are listed in Table 5, where marriages were classified into 8 groups according to whether the couples, husbands' parents or wives' parents were related or not, disregarding the degree of consanguinity.

At a glance on the table, it may be suggested that consanguinity between spouses has almost no effect on the infertility rate, whereas consanguinity between wives' parents has much greater effects than that of husbands' parents.

Next, the following linear regression model is set:

where $\mathrm{Y}$ denotes infertility rate,

$$
\mathrm{Y}=\mathrm{A}+\mathrm{B}_{\mathrm{o}} F_{\mathrm{o}}+\mathrm{B}_{\mathrm{p}} \mathrm{F}_{\mathrm{p}}+\mathrm{B}_{\mathrm{m}} F_{\mathrm{m}}
$$

A its mean,

$F_{0}, F_{p}$ and $F_{m}$ are respectively coefficients of parentage in Malécot's sense between the spouses, between the husbands' parents and between the wives' parents, and

$B_{0}, B_{p}$ and $B_{m}$ are respectively regression coefficients for the coefficients of parentage on infertility.

The results, shown on the left side of Table 6, indicate that the infertility rate decreases significantly with the increased degree of consanguinity between spouses, and increases highly significantly with the increased consanguinity between wives' parents, whereas the consanguinity between husbands' parents has almost no effect. 
Table 6. Effects of consanguinity on infertility rate. Results of regression analyses $\mathrm{Y}=\mathrm{A}+\mathrm{B}_{\mathrm{o}} \mathrm{F}_{\mathrm{o}}+\mathrm{B}_{\mathrm{p}} \mathrm{F}_{\mathrm{p}}+\mathrm{B}_{\mathrm{m}} \mathrm{F}_{\mathrm{m}}$

\begin{tabular}{lccc}
\hline & Whole sample & $(0,0,0)$ excluded \\
\hline $\mathrm{A}$ & & 0.0426 & 0.0170 \\
$\mathrm{~B}_{\mathrm{o}}$ & & $-0.1544^{* *}$ & 0.1432 \\
$\mathrm{~B}_{\mathrm{p}}$ & -0.0260 & 0.2021 \\
$\mathrm{~B}_{\mathrm{m}}$ & & $0.2140^{* * *}$ & $0.3681^{* *}$ \\
\hline B/A ratios & $\mathrm{B}_{\mathrm{p}} / \mathrm{A}$ & - & 11.9 \\
& $\mathrm{~B}_{\mathrm{m}} / \mathrm{A}$ & 5.0 & 21.7 \\
\hline
\end{tabular}

Significant at the $1 \%(* *)$ and $0.1 \%(* *)$ levels.

Table 7. Genetic load expressed by parental inbreeding.

\begin{tabular}{|c|c|c|c|}
\hline \multirow[t]{2}{*}{ Genetic load } & \multicolumn{2}{|c|}{ Equivalents per gamete } & \multirow[t]{2}{*}{ B/A ratio } \\
\hline & $\mathrm{B}$ & $\mathrm{B}+\mathrm{A}$ & \\
\hline \multicolumn{4}{|l|}{ Maternal inbreeding } \\
\hline Lethal, for prenatal death & $0.17-0.37$ & $0.20-0.44$ & $3.9-5.5$ \\
\hline Detrimental, for cerebral palsy & $0.017-0.035$ & $0.018-0.037$ & 17.3 \\
\hline \multicolumn{4}{|l|}{ Detrimental, for congenital } \\
\hline hip dislocation & 0.083 & 0.088 & 16.6 \\
\hline Infertility, for females & $0.21-0.37$ & $0.26-0.39$ & $5.0-21.7$ \\
\hline \multicolumn{4}{|l|}{ Paternal inbreeding } \\
\hline Infertility, for males & 0.20 & 0.22 & 11.9 \\
\hline
\end{tabular}

The table indicates that the infertility rate is rather high in the $(0,0,0)$ group in which all three couples in the two generations are unrelated. This group probably includes immigrants, and, therefore, is somewhat different from other groups in socioeconomic status. Moreover, the $(0,0,0)$ group makes about two-thirds of the whole sample, and undoubtedly contributes too much to the mean.

Thus, a further regression analysis was carried out by omitting the $(0,0,0)$ group, and the results are shown on the right side of Table 6 . In this case, consanguinity between wives' parents increases the infertility rate significantly and that between husbands' parents increases it but insignificantly, whereas consanguinity between spouses has substantially no effect.

\section{GENETIC LOADS EXPRESSED BY PARENTAL INBREEDING}

Genetic loads detectable by parental inbreeding may be estimated using values obtained above. According to Morton, Crow and Muller (1956), the number of lethal equivalents per gamete will lie between the $B$ and $B+A$, where $B$ is the regression coefficient of mortality on inbreeding coefficient and $A$ is the mean mortality. Morton (1960) extended the concept of lethal equivalents to "detrimental equivalents," and Tanaka (1964) proposed an analogous concept of "sterility equivalents," all equivalents being estimated by similar procedures. 


\section{Lethal equivalents for prenatal death expressed by maternal inbreeding}

Four regression coefficients for prenatal death on maternal inbreeding were estimated for each of the two populations (Tables 3 and 4). If the four intermediate values of the eight coefficients are adopted, an average gamete is estimated to carry $0.17-0.44$ equivalents of such harmful genes. Most of the estimated $B_{m} / A$ ratios cluster between 3.9-5.5 (Table 7). In view of numerous other factors affecting fetal viability such as environmental causes, chromosomal abnormalities, dominant or sex-linked recessive lethal mutations and autosomal recessive lethal homozygosity in the fetuses, the true ratio of inbreeding load to random load would be much greater than the above estimated $\mathrm{B}_{\mathrm{m}} / \mathrm{A}$ ratios. If the hypothesis of Morton, Crow, and Muller (1956) is accepted, a large part of the genetic load expressed as prenatal deaths through maternal inbreeding belongs to the mutational load.

\section{Infertility equivalents expressed by inbreeding}

As shown above, in order to estimate the effects of increased homozygosity in husbands and wives on the rate of couples never pregnant among those cohabiting for five years or longer, two regression analyses were carried out, one using the whole sample and the other excluding the $(0,0,0)$ group, in which the couples, the husbands' parents and the wives' parents are all unrelated.

If the $(0,0,0)$ group is included, the regression coefficient for infertility on wives' inbreeding is positive and highly significant, whereas that on husbands' inbreeding is negative and far from the significance level. On the other hand the calculation carried out by omitting the $(0,0,0)$ group indicates that the inbreeding of wives increases the infertility rate significantly and that of husbands also increases it, but insignificantly. Thus, the infertility equivalents per gamete expressed by inbreeding in females are estimated to be $0.21-0.39$ by the first and second analyses and those expressed by inbreeding in males $0.20-0.22$ using face values obtained by the second analysis (Table 7).

The average increases of infertility for inbreeding coefficient $=1$ of male and female spouses, $\mathrm{B}$, are respectively 11.9 and 21.7 times as large as the mean infertility rate, $A$, if the $(0,0,0)$ group is excluded, and the increase for female spouses is 5.0 times if the $(0,0,0)$ group is included. Moreover, the A term includes infertility due to environmental, chromosomal, and other causes undetectable by the inbreeding study. Thus, the data at hand may suggest that the loci responsible for infertility are largely concerned with the mutational load.

3. Genetic loads for congenital abnormalities expressed by maternal inbreeding

Kimura (1958) proposed a method to obtain the maximum likelihood estimate of genetic loads using data on proportions of marriages with the relationship in the general populations and in the parents of patients. Substantially the same procedure is used to estimate detrimental equivalents and $B / A$ ratios for congenital abnormalities expressed by maternal inbreeding. If the frequencies of an abnormality among children born to inbred mothers (i.e. mothers born to consanguineous marriages) and non-inbred mothers (i.e. mothers born to non-consanguineous marriages), respec- 
tively, are $P_{i}$ and $P_{n}$, and the frequency of inbred mothers in the general population is $\mathrm{C}$, the proportion of the inbred among mothers of children affected with the abnormality may be given by

$$
\mathrm{K}=\frac{\mathrm{CP}_{\mathrm{i}}}{\mathrm{CP}_{\mathrm{i}}+(1-\mathrm{C}) \mathrm{P}_{\mathrm{n}}},
$$

whence we obtain

$$
\begin{aligned}
& \frac{P_{i}}{P_{n}}=\frac{K(1-C)}{C(1-K)} \text {, or } \\
& \frac{P_{i}-P_{n}}{P_{n}}=\frac{K-C}{C(1-K)},
\end{aligned}
$$

If all the inbred mothers are products of first-cousin marriages, Formula (1) may give the rate of the increase in the frequency of the abnormality due to maternal inbreeding corresponding to first-cousin marriages $(F=1 / 16)$. Since, we have reasons to assume that inbred men and inbred women are equal in number in the general population and marry at equal rates, and that inbreeding of fathers has no effects on the formation of congenital abnormalities, the frequency of inbred mothers in the general population, C, may be approximately equal to the proportion of the inbred among fathers of the affected children. Thus, the ratio $B / A$ for $F=1$ may be estimated by putting the frequencies of first-cousin marriages among paternal and maternal grandparents respectively into $\mathrm{C}$ and $\mathrm{K}$ in the following equation:

$$
\mathrm{B} / \mathrm{A}=16(\mathrm{~K}-\mathrm{C}) /(1-\mathrm{K})
$$

Since $C=0.0334$ and $K=0.0671$ for cerebral palsy as shown in Table 1 , the ratio is estimated to be 17.30. Similarly, B/A is estimated to be 16.61 for congenital hip dislocation and 1.18 for albinism. The values are negative for paralytic poliomyelitis and severe mental defect. Data for phenylketonuria are too meager to be subjected to such calculation.

If the frequency of the abnormality among children born to non-inbred mothers, $P_{n}$, is known, the estimate of detrimental equivalents per gamete may lie between $P_{n} B / A$ and $P_{n}(B+A) / A$ or $P_{n}\{(B / A+1\}$. The incidence of cerebral palsy is reported to be $0.1-0.2 \%$ (Arima et al., 1964) and that of congenital hip dislocation $0.5 \%$ (Ishida and Morishita, 1976). If these values are put into $P_{n}$, the detrimental equivalents per gamete responsible for these two abnormalities expressed by maternal inbreeding may be estimated to be $0.017-0.035$ and $0.083-0.088$, respectively. Since the incidence of the abnormalities in the general infant population may be higher than among children born to non-inbred mothers, $P_{n}$, if the maternal inbreeding effects exist, the above estimated detrimental equivalents are possibly slight overestimates.

\section{DISCUSSION}

Adverse effects of increased homozygosity of zygotes on fertility and those of mothers on mortality and morbidity in their offspring seem to have been established 
in experimental and domestic animals. Doney and Smith (1968), for instance, compared the fertility of inbred ews (products of father-daughter cross) and that of their non-inbred half-sibs. Of a total of forty-one inbred ewes run with tested rams at normal mating time, sixteen $(39 \%)$ were unlikely to have carried a lamb to term due to non-ovulation, non-cleavage or abnormal cleavage of ova and nonviability of early implanted embryos. Out of twenty-six non-inbred half-sibs of similar ages, only one potentially infertile ewe was found (non-ovulation).

According to Falconer (1960), about $40 \%$ of the total inbreeding depression of litter size in mice is attributable to reduced fertility of the females. Similar observations were reported by McCarthy (1967). The inbreeding of the father did not influence the size of the litter sired. Chai $(1969,1970)$ pointed out that the effects of the intra-uterine environment of inbred mothers on the developing zygotes are important causes of increased rate of infertility, mortality and congenital malformations in inbred lines of rabbits.

Similar mechanisms have been suggested in man by Schull (1959), Yamaguchi et al. (1975), Richards (1975) and others, as well as the present author and his colleagues $(1964,1967,1968,1972)$. However, there are surprisingly few such data for man. The present study shows that increased homozygosity in maternal genotype may increase the frequency of some congenital abnormalities, such as cerebral palsy and congenital hip dislocation, but there is no indication of increase in severe mental defectives, albinos and phenylketonurics among offspring of inbred mothers.

The only comparable data so far published are those of Freire-Maia and Krieger (1975), who applied a multiple regression model to analyze the effects of inbreeding of zygotes, mothers and fathers on number of pregnancies, anomalies, pre- and postnatal mortality, and fertility. A significant effect (at the $5 \%$ level) of maternal inbreeding was found on "anomalies"; however, the maternal inbreeding variable did not enter the final regression model because it did not affect the regression mean square in a significant manner. As shown by the present study, maternal inbreeding may have effects on some abnormalities, but almost no effects on others. Reanalyses of their data separated into individual abnormalities may be desirable.

The result, that the present study shows no indication of maternal inbreeding effects on mental retardation, may be compatible with findings of Perry et al. (1970) who found no metabolic disorder among 152 mothers of mental defectives of unknown aetiology. Obviously, these results by no means disprove the possibility that autosomal recessive homozygosity in mothers has an adverse effect on mental development of the fetuses.

Normally intelligent phenylketonurics have occasionally been found among relatives of typical phenylketonuria patients (Woolf et al. 1961, and many others). An extraordinary case (a brother of a typical phenylketonurics) was reported by Isogai et al. (1964). He had an IQ of 103, graduated from a national university and became a staff member in an industrial laboratory, having no neurological nor psychological abnormalities. He was examined as a relative of his affected brother and unex- 
pectedly proved to be a classical phenylketonuric.

Besides the well established effects of maternal phenylketonuria on fetuses, Lyon et al. (1974) reported a case of histidinemic mother with an 105-115 IQ, who had 4 mentally retarded children, possibly attributable to the maternal biochemical abnormality.

These facts show that some cases of mental deficiency of unknown aetiology may be due to unrecognized biochemical disorder in the mothers with normal or near normal intelligence (Hooft et al., 1970; and others). Since a majority of hereditary inborn errors of metabolism are inherited as autosomal recessives, consanguineous marriage must increase children affected with such disorders and was expected to increase mentally retarded grandchildren.

The results of the present study, that there is no increase in consanguinity rate in maternal grandparents over that in paternal grandparents, indicate only that the proportion of mental defectives due to maternal inbreeding is too small to be detectable by the method used here.

The present data suggest that increased maternal inbreeding may increase the mortality of the fetuses, though inconclusive. Schull (1959) pointed out a possible effect of maternal inbreeding on the rate of stillbirth in Hiroshima and Nagasaki reporting that, if the spouses are unrelated, of 150 pregnancies of inbred mothers, 3 or $2.31 \%$ terminated in stillbirths, and of 62 pregnancies of non-inbred mothers, no stillbirth was observed, whereas the rate of stillbirth was $1.42 \%$ in all unrelated spouses and $1.54 \%$ in the related spouses. These findings seem to support the prediction that fetal survival is dependent on the maternal rather than the fetal genotype.

More recently, the effects of maternal inbreeding on the mortality of offspring were studied in two large samples in Kyushu, Japan. Schull et all. (1970a) analyzed data collected in Hirado Island and showed that a slight, insignificant increase of stillbirths and a significant increase of prereproductive mortality among conceptions surviving at least 21 weeks of gestation was correlated with maternal inbreeding in nonfarm families married in the years 1920-1939.

Yamaguchi et al. (1975) showed that postnatal mortality of children was significantly increased with increased maternal inbreeding. The effects were more prominent in the first year than in the later years of life, suggesting that the effects were expressed early after birth. No effect of paternal inbreeding on mortality of offspring was disclosed by either Schull et al. or Yamaguchi, et al.

On the other hand, Warburton and Fraser (1964) reported that the rate of abortions was $14.8 \%$ among 290 pregnancies in consanguineous marriages, $14.5 \%$ among 131 pregnancies in couples whose wives were products of consanguineous marriages, and $13.3 \%$ among 83 pregnancies in couples whose husbands were products of consanguineous marriage, indicating no statistical difference among the groups. However, their data were too meager to disprove the possibility of the effects of maternal inbreeding on fetal mortality. Freire-Maia and Krieger (1975) could find no significant increase in the rates of abortions, stillbirths and postnatal deaths connected 
with parental inbreeding.

The present study showed highly significant increases of the rates of nonpregnant couples with increased inbreeding in wives. However, Schull et al. (1970b), Yamaguchi et al. (1975), and Freire-Maia and Krieger (1975) could not find no indication of such effects.

These discrepancies among investigators may have resulted from various causes. The pre- and postnatal mortality, infertility, and congenital abnormalities such as cerebral palsy and mental deficiency are extremely heterogeneous in their aetiology and those due to increased homozygosity of the mothers may be only a minor portion of each variable. Thus, the effects of maternal inbreeding, if any, may not be easily detectable if the proportions of deaths, abnormalities or infertility due to other causes are too large.

Therefore, in order to elevate the efficiency of the test, deaths, etc. due to causes other than maternal inbreeding should be excluded from the sample as completely as possible, as shown in the present study in which the analyses for mental deficiency were carried out excluding Down's syndrome, other known hereditary syndromes, psychopathics, and those acquired postnatally.

Populations with high mortality may be less suitable for such study, since a majority of early deaths in such populations are due to environmental causes. The fact that the effects of consanguineous marriage on mortality in offspring born to such marriage was observed in Japanese populations (Schull and Neel, 1965; Schull et al., 1970a; Yamaguchi et al., 1970; Tanaka, 1973; Yanase et al., 1973), but not in a Brasilian population (Freire-Maia and Krieger, 1975) may possibly be a reflection of the difference in the rate of early deaths between the two countries. A similar argument may be advanced to explain the different trends in the effects of maternal inbreeding on mortality in different populations.

For sterility, the voluntary ones must be excluded, though such sterility, if any, seems to be exceptional in the samples analyzed in the present study.

Obviously, reliability of the data is one of the most important factors. Tanaka et al. (1967) pointed out that significantly lower prenatal mortality rates were estimated for couples who had married before 1930 than for later married couples. Schull et al. (1970a) reported that the frequency of stillbirths was significantly and inversely related to the number of years of marriage or cohabitation. Since there is no indication that natural stillbirths are on the increase in Japan, these two observations were ascribed to a lessened recall on the part of older mothers. Thus, Tanaka et al. (1967) and the present author carried out the analyses excluding early married couples from the samples. Observations of Schull et al. (1970a), that the frequency of stillbirths was increased with increasing socioeconomic status, may be a reflection of greater recall in couples of higher socioeconomic status (especially, higher education level) compared to those of lower status. Such biases may be inevitable, if the informations depend upon interviews and questionnaires.

Information on consanguinity is not uncommonly reported erroneously by 
married couples (Yanase, 1962; Schull and Neel, 1965; Nakamoto, 1969; Schull et al., 1970a). Most of the Japanese data on consanguinity have been checked by referring to koseki records and, therefore, may be much more reliable than those dependent on interviews or questionnaires alone.

The causes of early deaths, sterility and congenital abnormalities are largely unknown, but are undoubtedly heterogeneous. The methods described in the present paper may be useful tools for clarifying a part of the aetiologies, i.e., the effects of harmful genes, which reduce the fertility in the homozygotes or increase the mortality and morbidity in the offspring of homozygous mothers.

\section{SUMMARY}

The rate of first cousin marriages among maternal grandparents of 460 cerebral palsied patients is significantly higher than the rate among paternal gransparents, suggesting that increased maternal homozygosity may provide an unfavorable intrauterine environment for the fetus to induce the congenital abnormality. A similar increase of consanguinity is observed among maternal grandparents of 198 patients with congenitally dislocated hip, but the increase is not significant, possibly because of small sample size.

There are no such indications of the increased consanguinity rate in maternal grandparents of 328 paralytic poliomyelitics, 273 severe mental defectives, and patients with autosomal recessive disorders, such as phenylketonuria and albinism.

Data on the relationship of prenatal mortality among 3,357 pregnancies with consanguinity between the spouses, between the husband's parents and between the wife's parents were analyzed. Eight set of regression analyses disclose that the mortality is increased consistently, but insignificantly, with the wife's inbreeding coefficient, whereas consanguinity between the spouses and between the husband's parents show no consistent relationship with the prenatal mortality.

Regression analyses were used to study the effects of consanguinity on infertility in 1,662 couples cohabiting for five years or longer. The results indicate that the infertility rate for couples for whom there has never been a pregnancy is highly significantly increased with increasing inbreeding coefficient of the wife, but inconsistently and insignificantly with increasing inbreeding coefficient of the husband.

Lethal equivalents for the prenatal deaths expressed in offspring of inbred mothers are estimated to be $0.17-0.44$ per gamete. Detrimental equivalents expressed in offspring of inbred mothers are estimated to be $0.017-0.037$ for cerebral palsy and 0.083-0.088 for congenital hip joint dislocation. Infertility equivalents expressed in the inbred females is estimated to be $0.21-0.39$ per gamete and those in the inbred males $0.20-0.22$ per gamete. The data at hand suggest that these genetic loads are maintained in the population largely by mut7tion-selection equilibria.

The approaches described here may be useful tools to discriminate between the effects of inbreeding and other effects on disorders with heterogeneous aetiologies. 
Sources of contradictional results obtained by different investigators and the method to increase the efficiency of detecting the inbreeding effects were discussed.

Acknowledgment The author is indebted to Drs. Toshiyuki Yanase and Toshiyuki Furusho for their generosity in making available data, and to Drs. Masaharu Fujino, Tatsuo Mochizuki, Minoru Tada, Hideho Okumura, and Mr. Fujio Tateyama for their cooperation in providing the lists of crippled and mentally retarded children. He is grateful to Dr. the late Taku Komai, and Drs. Ei Matsunaga, Motoo Kimura, William J. Schull, James V. Neel, Masatoshi Nei, Koichi Ito, and Akio Kudo for their valuable advice.

Particular thanks are due to Miss Sadako Takahashi and Miss Fujiko Oi for their accomplishments of koseki study, to Miss Naomi Ohtsuki for her cooperation, and to Mrs. Miyoko Fujisawa for the preparation of the manuscripts.

\section{REFERENCES}

Arima, M., Komiya, K., and Suzuki, Y. 1964. Aetiology of the cerebral palsy (in Japanese). Clin. Neurol. 4: 314-318.

Chai, C.K. 1969. Effects of inbreeding in rabbits: inbred lines, discrete characters, breeding performance, and mortality. J. Hered. 60: 64-70.

Chai, C.K. 1970. Effect of inbreeding in rabbits. Skeletal variations and malformations. $J$. Hered. 61: 3-8.

Doney, J.M. and Smith, W.F. 1968. Infertility in inbred ewes. J. Reprod. Fertil. 15: 27.7-282.

Falconer, D.S. 1960. The genetics of litter size in mice. J. Cell. Comp. Physiol. 56, Suppl. 1: 153-167.

Fisch, R.O. and Anderson, J.A. 1971. In "Phenylketonuria" (Bickel, Hudson, and Woolf, eds.), Verlag, Stuttgart, cited from Pitt and Gooch.

Fraser, F.C. 1961. The use of teratogens in the analysis of abnormal development mechanisms. First International Congress on Congenital Malformations (Intern. Med. Congr., ed.), Lippincott, Philadelphia.

Fraser, F.C. 1974. Some aspects of maternal effects on congenital malformations. In "Congenital Defects" (D.T. Janerich, R.G. Skalko and I.H. Porter, eds.), pp. 17-22. Acad. Press, New York.

Freire-Maia, A. and Krieger, H. 1975. Human genetic studies in areas of high natural radiation. VIII. Genetic load not related to radiation. Am. J. Human Genet. 27: 385-393.

Hooft, C., Carton, D., and Broekaert, E. et al. 1970. Les enfants de mères phénylcétonuriques. Acta Paediat. Belg. 24: 5-19.

Ishida, K. and Morishita, S. 1976. Japan, a high incidence country of congenital dislocation of the hip (Personal communication).

Isogai, I., Fukuhara, R., and Utena, H. 1964. Nervous and mental symptoms observed in heterozygotes for phenylketonuria (in Japanese). Seishin-lgaku 6: 509-514.

Kimura, M. 1958. Theoretical basis for the study of inbreeding in man (in Japanese with English summary). Jap. J. Human Genet. 3: 51-70.

Lyon, I.C.T., Gardner, R.J.M., and Veale, A.M.O. 1974. Maternal histidinaemia. Arch. Disease Childh. 49: 581-583.

McCarthy, J.C. 1967. The effects of inbreeding on the components of litter size in mice. Genet. Res. 10: 73-80.

Morton, N.E. 1960. The mutational load due to detrimental genes in man. Am. J. Human Genet. 12: 348-364.

Morton, N.E., Crow, J.F., and Muller, H.J. 1956. An estimate of the mutational damage in man from data on consanguineous marriages. Proc. Nat. Acad. Sci. 42: 855-863. 
Nakamoto, N. 1969. A study of consanguinity in Fukuoka, an urban population of large sizemating patterns and degree of inbreeding (in Japanese with English summary). Fukuoka Acta Med. 60: 184-209.

Perry, T.L., Bunting, R., and Tischler, B. et al. 1970. Unrecognized maternal biochemical disease: An uncommon cause of mental retardation in children. J. Ment. Defic. Res. 14: 44-48.

Pitt, D. and Gooch, J. 1974. The problem of maternal phenylketonuria. Aust. Paediat. J. 10: 337-342.

Richards, B.W. 1975. Observations on the familial appearance of diseases associated with metabolic disorders of the mother. Ann. Human Genet. 39: 189-191.

Schull, W.J. 1959. Inbreeding effects on man. Eugen. Quart. 6: 102-109.

Schull, W.J., Nagano, H., Yamamoto, M., and Komatsu, I. 1970a. The effects of parental consanguinity and inbreeding in Hirado, Japan. I. Stillbirths and prereproductive mortality. Am. J. Human Genet. 22: 239-261

Schull, W.J., Furusho, T., Yamamoto, M., Nagano, H., and Komatsu, I. 1970b. The effect of parental consanguinity and inbreeding in Hirado, Japan. IV. Fertility and reproductive compensation. Humangenetik 9: 294-315.

Schull, W.J. and Neel, J.V. 1965. The Effects of Inbreeding on Japanese Children. Harper \& Row, New York.

Tanaka, K. 1964. Effect of consanguinity on the fertility in man (Abstract, in Japanese). Jap. J. Genet. 39: 371.

Tanaka, K. 1966a. Effects of maternal inbreeding on cerebral palsy (Abstract, in Japanese). Jap. J. Human Genet. 11 : 112.

Tanaka, K. 1966b. Effect of maternal genotype on infertility and prenatal death in man, with special consideration of effect of mutation (in Japanese). Basic Studies on Genetic Hazards of Mutations in Populations (D. Moriwaki, ed.), pp. 12-18.

Tanaka, K. 1967. The role of maternal genotypes as causes of congenital abnormalities (in Japanese). Annual Reports of Scientific Research Grants, Ministry of Education 1966, Medicine and Pharmacy, pp. 595-596.

Tanaka, K. 1968. Genetics of phenylketonuria (in Japanese). Advances in Neurol. Sci. 12: 133-135.

Tanaka, K. 1971. Possible systematic errors in consanguinity rate estimated from the study of Japanese family register, koseki. Jap. J. Human Genet. 15: 219-230.

Tanaka, K. 1972. Possible effects of maternal inbreeding on congenital abnormalities and mental retardation in man. Jap. J. Human Genet. 16: 170-181.

Tanaka, K. 1973. Genetic studies on inbreeding in some Japanese populations. XI. Effects of inbreeding on mortality in Shizuoka. Jap. J. Human Genet. 17: 319-331.

Tanaka, K., Furusho, T., Murai, M., and Yokoo, J. 1968. Possible effects of maternal inbreeding on fertility, fetal survival and congenital abnormalities in man (Abstract). Proc. XII Intern. Congr. Genet. I: 298.

Tanaka, K., Matsunaga, E., Handa, Y., Murata, T., and Takehara, K. 1961. Phenylketonuria in Japan. Jap. J. Human Genet. 6: 65-77.

Tanaka, K. and Ohtsuki, N. 1965. Effect of inbreeding on fetal deaths in man (Abstract, in Japanese). Jap. J. Genet. 40: 421.

Tanaka, K., Ohtsuki, N., and Furusho, T. 1967. Effects of maternal inbreeding on prenatal deaths in man. Proc. Jap. Acad. 43: 801-806.

Tanaka, K. Yanase, T. and Furusho, T. 1964. Effects of inbreeding on fertility in man. Proc. Jap. Acad. 40: 852-856.

Tanaka, K. and Watanabe, K. 1967. Frequency of albinos in Japanese population (in Japanese with English summary). Jap. J. Human Genet. 11: 231-243.

Warburton, D. and Fraser, F.C. 1964. Spontaneous abortion risks in man. Data from reproduc- 
tive histories collected in a medical genetics unit. Am. J. Human Genet. 16: 1-25.

Woolf, L.I., Ounsted, C., Lee, D., Humphrey, M., Cheshire, N.M., and Steed, G.R. 1961. Atypical phenylketonuria in sisters with normal offspring. Lancet 2: 464 .

Yamaguchi, M., Yanase, T., Miyake, M., Nagano, H., and Nakamoto, N. 1975. Effects of paternal and maternal inbreeding on mortality and sterility in the Fukuoka population. Jap. J. Human Genet. 20: $123-130$.

Yanase, T. 1962. The use of the Japanese family register for genetic studies. In "The Use of Vital and Health Statistics for Genetic and Radiation Studies," Proc. Seminar sponsored by the United Nations and W.H.O. pp. 119-132. United Nations, New York.

Yanase, T., Fujiki, N., Handa, Y., Yamaguchi, M., Kishimoto, K., Furusho, T., Tsuji, Y., and Tanaka, K. 1973. Genetic studies on inbreeding in some Japanese populations. XII. Studies of isolated populations. Jap. J. Human Genet, 17: 332-366. 